\title{
The need for a new journal: European Orthopaedics and Traumatology
}

\author{
Wolfhart Puhl
}

Published online: 29 April 2010

(C) EFORT 2010

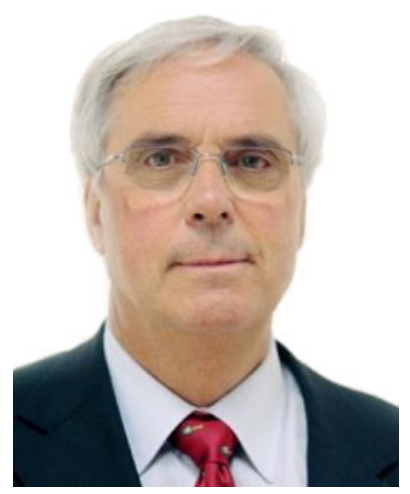

EFORT came into existence as a consequence of the emergence of Europe as a political entity.

One difficulty concerning our daily work in the sense of a network of the European orthopaedic family is that we use different languages, work in different health-care systems and, to some extent, have different training and education.

Therefore one of the main intentions and duties of EFORT is to harmonise orthopaedics and musculo-skeletal traumatology in Europe through education.

Education in the sense of an European network requires communication, and since its inception EFORT has been dedicated to this, with many activities such as instructional courses, fora, expert-meets-expert symposia and, of course, congresses.

\section{W. Puhl ( $\square)$}

Orthopädische Spezialklinik Oberstdorf,

Trettachstrasse 16,

87561 Oberstdorf, Germany

e-mail: wolfhart.puhl@efort.org

It was soon realised that these activities will reach only a small proportion of Europe's orthopaedic surgeons. Education with the intention of harmonisation is not sufficient.

Therefore it became obvious from an early stage that we need a communication channel for all of us, in the form of an internet-based EFORT journal which is given free of charge to each EFORT member.

By the time of the 11th EFORT Congress on 2-5 June 2010 in Madrid, after a great deal of work, the first step will have been taken and you will be able to hold in your hands the first issue of the official EFORT journal: European Orthopaedics and Traumatology

The journal aims to become a platform for the entire field of orthopaedics and traumatology in Europe and beyond. It is constructed to give the best communication possibilities between member societies and EFORT.

Beyond common orthopaedics and traumatology we do have in Europe our specialty societies, some with their own journals, to bring the specialists together in a close-knit group of experts dedicated to one particular topic.

With a little insight into the situation of the umbrella organisation EFORT and the specialty societies it is obvious that there is no real conflict potential between them. In this sense all experienced, "specialised" orthopaedic surgeons of Europe are heartily invited to actively participate as section editors and reviewers in all activities of our journal to present their work and educate general orthopaedic surgeons in the necessary way.

The process of building up our journal has started long before the presentation of this first issue, and we all have to thank our participating colleagues for their input. The process of selecting section editors and reviewers has started, but of course not finished, and indeed it never will be ended because it is a continuous process of selecting the most experienced and most active people. Those active and 
highly experienced colleagues will in the future be members of the EFORT Scientific Academy, the power tool of EFORT for the whole spectrum of scientific activities.

Especially the editors and reviewers, but in principle all of you, are asked to contribute controversial discussions, ideas for topics to be discussed, interesting case reports, original papers and reviews as a start for further publications and discussions to the journal. Today the journal is the start to enable improved communication for better education and hopefully harmonisation of orthopaedics and traumatology in Europe.

Colleagues from outside Europe are heartily invited to participate in this process.

Besides the scientific part of our journal we should realise that daily work and a successful evolution in Europe cannot be achieved without realising the necessary active contacts between us and industry in research and development. In this sense the journal is of course open for reviewed publications from industry.
In addition, EFORT as a European federation has the duty to work towards a positive evolution of health-care in Europe, representing the interests of our member societies and also the specialty societies in the political field of Europe. In this sense expected future discussions, running discussions, decisions from the political field of Europe have to be presented to the European orthopaedic family via our journal.

The journal will not only offer a forum for discussion among orthopaedic surgeons and all those working with them but will also, necessarily, be a channel of communication with patient organisations.

European Orthopaedics and Traumatology provides a platform for excellent basic and clinical research in orthopaedics and all related disciplines.

Reflecting EFORT's intention to connect members of all different societies and its commitment to rapid dissemination of significant new research and practices, the ejournal is available free of charge to all members.

W.Puhl

Editor-in-Chief 